\title{
Further Identification and Characterization of Products Processed from the Coronavirus Avian Infectious Bronchitis Virus (IBV) 1a Polyprotein by the 3C-like Proteinase
}

\author{
LISA F. P. NG, H. Y. XU, AND D. X. LIU \\ Institute of Molecular Agrobiology, The National University of Singapore, 1 Research Link, \\ Singapore 117604
}

\section{INTRODUCTION}

Proteolytic processing of the IBV $441-\mathrm{kDa}$ la and $741-\mathrm{kDa}$ la/ $1 \mathrm{~b}$ fusion polyproteins to smaller mature products is mediated by two viral proteinases, namely, the papain-like proteinase and the 3C-like proteinase (Fig. 1). The $3 \mathrm{C}$-like proteinase was identified as a $33-\mathrm{kDa}$ protein in IBV-infected Vero cells (Lim et al., 2000). Characterization of the proteinase activities has shown that it cleaves the bulk of the polyproteins at conserved Q-S (G and $\mathrm{N}$ ) dipeptide bonds, resulting in the release of more than ten mature products (Liu et al., 1994, 1997, 1998; $\mathrm{Ng}$ and Liu, 1998, 2000). It was shown to be associated with the membrane fraction in virus-infected cells by both cellular and biochemical studies ( $\mathrm{Ng}$ and Liu, 2000).

In this report, we confirm the presence of three more cleavage products of 34, 6 and $16 \mathrm{kDa}$. Taken together with the previously identified 24- and 10-kDa proteins (Ng and Liu, 1998; Liu et al., 1997; Lim et al., 2000), five products were released from the 1a polyprotein by the $3 \mathrm{C}$-like proteinase, in addition to the $33-\mathrm{kDa}$ proteinase itself. Subcellular localization of the five products in virus-infected cells shows fluorescence at the perinuclear region with granular and vesicular staining, but distinct staining patterns were observed when the proteins were expressed individually in intact cells.

The Nidoviruses (Coronaviruses and Arteriviruses).

Edited by Ehud Lavi et al., Kluwer Academic/Plenum Publishers, 2001. 
These results suggest that interaction of the individual cleavage products may occur in virus-infected cells in order to form the membrane-bound viral replication complexes.

\section{MATERIALS AND METHODS}

\subsection{Virus and cells}

The egg-adapted Beaudette strain of IBV (ATCC VR-22), obtained from the American Type Culture Collection (ATCC), and was adapted to Vero cells and prepared as described previously ( $\mathrm{Ng}$ and Liu, 1998, 2000).

Vero cells and Cos-7 cells were grown at $37^{\circ} \mathrm{C}$ in $5 \% \mathrm{CO}_{2}$ and maintained in Dulbecco's modified minimal essential medium (Gibco BRL, Life Technologies) supplemented with $10 \%$ newborn calf serum.

\subsection{Radiolabeling of IBV-infected and mock-infected Vero cells}

Confluent monolayers of Vero cells grown on $60 \mathrm{~mm}$ dishes were infected with IBV at a multiplicity of infection of approximately $2 \mathrm{PFU} /$ cell. The cells were labeled for $4 \mathrm{~h}$ with $25 \mu \mathrm{Ci} / \mathrm{ml}\left[{ }^{35} \mathrm{~S}\right]$ methionine-cysteine at 6 $\mathrm{h}$ postinfection before harvesting.

\subsection{Radioimmunoprecipitation}

Radioimmunoprecipitation with polyclonal rabbit antisera was carried out as described previously (Liu et al., 1994).

\subsection{SDS-polyacrylamide gel electrophoresis}

SDS-PAGE was carried out with $15 \%$ and $17.5 \%$ polyacrylamide concentrations, and the labeled polypeptides were detected by autoradiography or fluorography of dried gels.

\subsection{Western Blot}

SDS-PAGE of viral polypeptides was carried out as mentioned and viral proteins were transferred to nitrocellulose membrane by the semi-dry method (Bio-Rad). The membrane was blocked overnight at $4^{\circ} \mathrm{C}$ in blocking 
buffer ( $5 \%$ milk in $20 \mathrm{mM}$ Tris-Cl 7.4, $150 \mathrm{mM} \mathrm{NaCl}, 0.1 \%$ Tween 20$)$ and incubated with specific polyclonal rabbit antiserum (anti-16) diluted in blocking buffer (1:500 dilution) at $\mathrm{RT}^{\circ} \mathrm{C}$ for $2 \mathrm{~h}$ and washed with TBST (20 $\mathrm{mM}$ Tris-Cl 7.4, $150 \mathrm{mM} \mathrm{NaCl}, 0.1 \%$ Tween 20). Membrane was blocked in blocking buffer for another $20 \mathrm{~min}$ and incubated with anti-rabbit IgG conjugated with horseradish peroxidase (Dako) diluted in blocking buffer $(1: 2500)$ at $\mathrm{RT}^{\circ} \mathrm{C}$ for $1 \mathrm{~h}$ followed by colour development (ECL, Amersham).

\subsection{Polymerase chain reaction (PCR)}

Appropriate primers and template DNAs were used in amplification reactions with cloned PFU DNA polymerase (Stratagene) under standard buffer conditions with $2 \mathrm{mM} \mathrm{MgCl} 2$.

\subsection{Indirect Immunofluorescence microscopy}

Cells were grown on coverslips and infected with IBV or transfected with appropriate plasmid DNAs. After washed with PBS containing $1 \mathrm{mM} \mathrm{CaCl}_{2}$ and $1 \mathrm{mM} \mathrm{MgCl} 2$ (PBSCM), the cells were fixed with $4 \%$ paraformaldehyde (in PBSCM) for $30 \mathrm{~min}$ at room temperature and permeabilized with $0.1 \%$ saponin (in PBSCM), followed by incubation with specific antiserum at room temperature for $2 \mathrm{~h}$. Antibodies were diluted in fluorescence dilution buffer (PBSCM with 5\% normal goat serum, 5\% newborn calf serum, and $2 \%$ bovine serum albumin, $\mathrm{pH}$ 7.6). The cells were then washed with PBSCM and incubated with anti-rabbit or anti-mouse $\operatorname{IgG}$ conjugated to fluorescein isothiocynate (Sigma) in the fluorescence dilution buffer at $4^{\circ} \mathrm{C}$ for $1 \mathrm{~h}$ before mounting.

\subsection{Construction of plasmids}

Plasmids pIBV9, pIBV3C and pBP5 were described before (Liu et al., 1994, 1997 and $\mathrm{Ng}$ and Liu, 2000). The IBV sequences present in these constructs are nucleotides 8693 to 10925,8865 to 9786 and 10752 to 12312 respectively.

Plasmids pT7tag34k and pT7tag16k cover nucleotides 9787 to 10662 and 11875 to 12309 , respectively were constructed by ligation of PCR fragments covering the appropriate regions into Nco I-digested pT7tag (contains an 11-amino-acid T7tag: MASMTGGQQMG). pT7tag34k was generated using pIBV9 as the template and LN-76 (5'-AGATTACCATGGC TTCTTTTGTAAGA-3') and LN-75 (5'-CTTGCCATGGAAACTGTA GCAATAGG-3') as the cloning primers. pT7tag16k was cloned using pBP5 
as the template and LN-9 (5'-TCTTACCATGGAGTCTAAAGGGCAT-3') and LN-70 (5'-AGCACCATGGAAACAG AAGATTTTGG-3') as the cloning primers.

\section{RESULTS AND DISCUSSION}

\subsection{Identification of two novel proteins in IBV-infected cells}

Previously, we have identified the $33-\mathrm{kDa} 3 \mathrm{C}$-like proteinase and two other cleavage products, the $24-$ and $10-\mathrm{kDa}$ proteins from the la polyprotein (Fig. 1; Lim et al., 2000; Ng and Liu, 1998; Liu et al., 1997). Recently, a $\mathrm{Q}^{3379}-\mathrm{A}^{3380}$ dipeptide bond was demonstrated to be a cleavage site of the 3C-like proteinase (Ng and Liu et al., 2000). Three more products with calculated molecular masses of 34,9 , and $16 \mathrm{kDa}$, respectively were expected to be released from cleavage by the $3 \mathrm{C}$-like proteinase at the $\mathrm{C}$ terminal region of the la polyprotein. Two region specific antisera were raised and similar approaches were used to study the protein expression. Anti-6, raised against the IBV sequence encoded between nucleotides 10666 and 10914 immunoprecipitated a specific product from IBV-infected Vero cells. The protein migrated on SDS-PAGE as a $6 \mathrm{kDa}$ protein instead of the estimated size of $9 \mathrm{kDa}$ (Fig. 2, lane 1). Western blot analysis with antiserum anti-16, raised against the IBV sequence encoded between nucleotides 11787 and 12312 resulted in the detection of a $16-\mathrm{kDa}$ protein from IBV-infected cells from $6 \mathrm{~h}$ p.i. onwards (Fig. 2, lanes 5 to 8). Both proteins are released by the $3 C$-like proteinase at $\mathrm{Q}^{3379}-\mathrm{A}^{3380} / \mathrm{Q}^{3462}-\mathrm{S}^{3463}$ and $\mathrm{Q}^{3783}-\mathrm{S}^{3784} / \mathrm{Q}^{3928}-\mathrm{S}^{3929}$ dipeptide bonds, respectively (Fig. 1).

This data was consistent with that from MHV and HCV (Bost et al., 2000; Ziebuhr and Siddell, 1999), thus the previously predicted $\mathrm{Q}^{3213}-\mathrm{G}^{3214}$ dipeptide bond is not a real cleavage site of the $3 \mathrm{C}$-like proteinase. Sitedirected mutagenesis and in vitro studies confirmed that this site is not used (data not shown). Cleavage at the $\mathrm{Q}^{3086}-\mathrm{S}^{3087}$ and $\mathrm{Q}^{3379}-\mathrm{A}^{3380}$ dipeptide bond would result in the release of a mature product of approximately $34 \mathrm{kDa}$ (Fig.1). Efforts to raise region specific antiserum to detect this product failed, possibly due to the presence of extremely hydrophobic amino acid residues. 

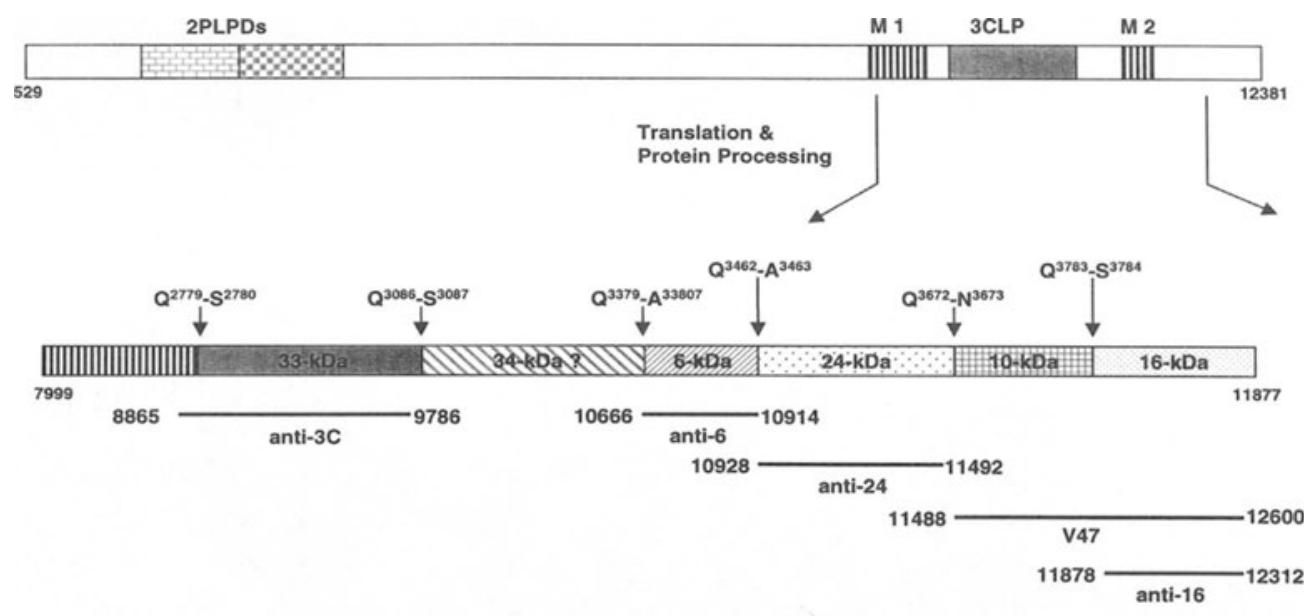

Figure 1. Diagram of ORFla, illustrating the two overlapping papain-like proteinase domains (PLPDs) and the 3C-like proteinase domain (3CLP).

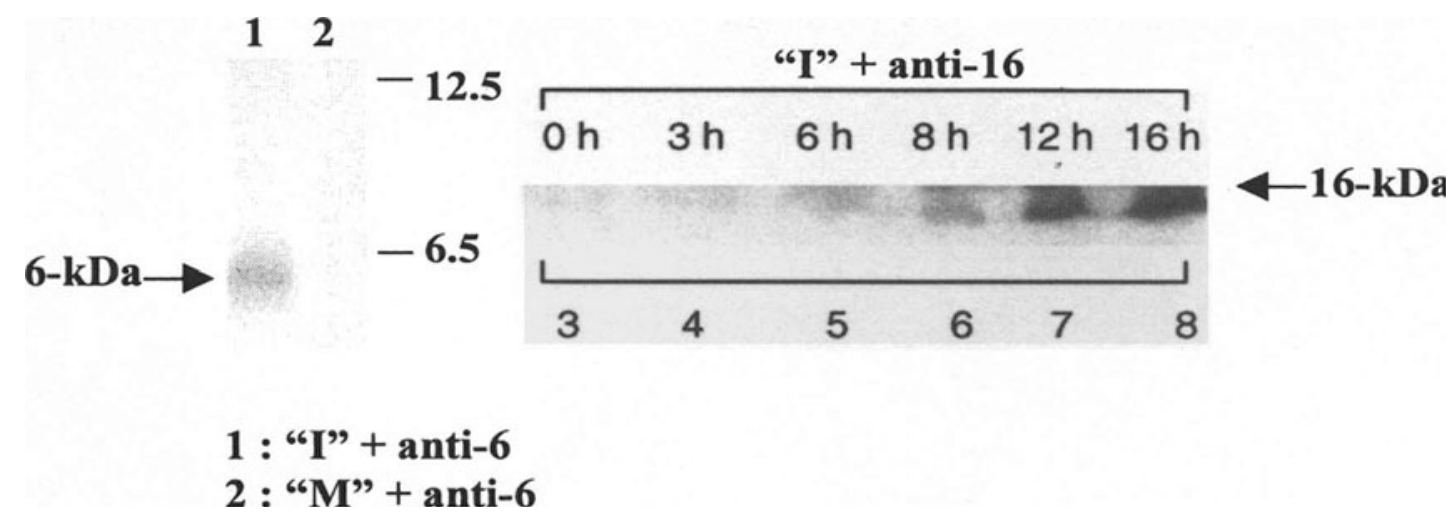

Figure 2. Detection of the 6- and 16-kDa proteins in IBV-infected Vero cells (I) with anti-6 (lanes 1 and 2) and anti-16 (lanes 3 to 8), respectively.

\subsection{Intracellular localization of the five viral products}

The subcellular localization of the five cleavage products was first studied by fusing the individual proteins with the green fluorescent protein 
(GFP). Transfection of Cos-7 cells with plasmids expressing the 34-, 24and $16-\mathrm{kDa}$ proteins showed that the three proteins are localized to intracellular membrane structures (Fig. 3B, D and F). However, transfection of Cos-7 cells with plasmids expressing the 6- and $10-\mathrm{kDa}$ proteins showed diffuse distribution patterns, which are similar to that of the GFP control (Fig. 3A, C and E).

Due to the absence of a specific antiserum, the $34-\mathrm{kDa}$ protein was tagged to a $\mathrm{T} 7 \mathrm{tag}$, and a highly specific anti-T7 monoclonal antibody (Novagen) was used to stain cells in indirect immunofluorescence assay. Cos-7 cells transfected with pT7tag29k showed perinuclear staining (Fig. 4A and B), confirming that this hydrophobic protein is associated with membrane compartments. Cos-7 cells expressing the 6- and 10-kDa proteins were stained with anti-6 and V47 respectively, showing cytoplasmic staining, suggesting that these two proteins are localized in the cytoplasm when expressed alone (Fig. 4C, D, G and H). Immunofluorescence of Cos-7 cells expressing the $24-\mathrm{kDa}$ protein with anti-24 showed perinuclear staining (Fig. 4E and F). Positive staining was observed on nonpermeabilized Cos-7 cells transfected with pT7tag16k (Fig. 4J), suggesting that the $16-\mathrm{kDa}$ protein may be transported to the cell surface. In permeabilized cells, the $16-\mathrm{kDa}$ protein appeared to be localized in the perinuclear region (vesicles) (Fig. 4L). Immunofluorescence with the respective antisera on nontransfected Cos-7 cells gave negative staining (Fig. 4I and K).

Finally, immunostaining of IBV-infected Vero cells with anti-6, anti-24, V47 and anti-16, respectively, clearly showed fluorescence at the perinuclear region with punctate and vesicular staining (Fig. 5B, D, F and H). Mockinfected cells did not give similar profiles (Fig. 5A, C, E and G).

\section{CONCLUSION}

The 34-, 6-, 24-, 10- and 16-kDa proteins may interact in virus-infected cells together with the $3 \mathrm{C}$-like proteinase to form the membrane-bound viral replication complexes.

\section{REFERENCES}

Bost, A. G., Carnahan, R., Lu, X. T., and Denison, M. R., 2000, Four proteins processed from the replicase gene polyprotein of mouse hepatitis virus colocalize in the cell periphery and adjacent to sites of virion assembly. J. Virol. 74: 33793387. 

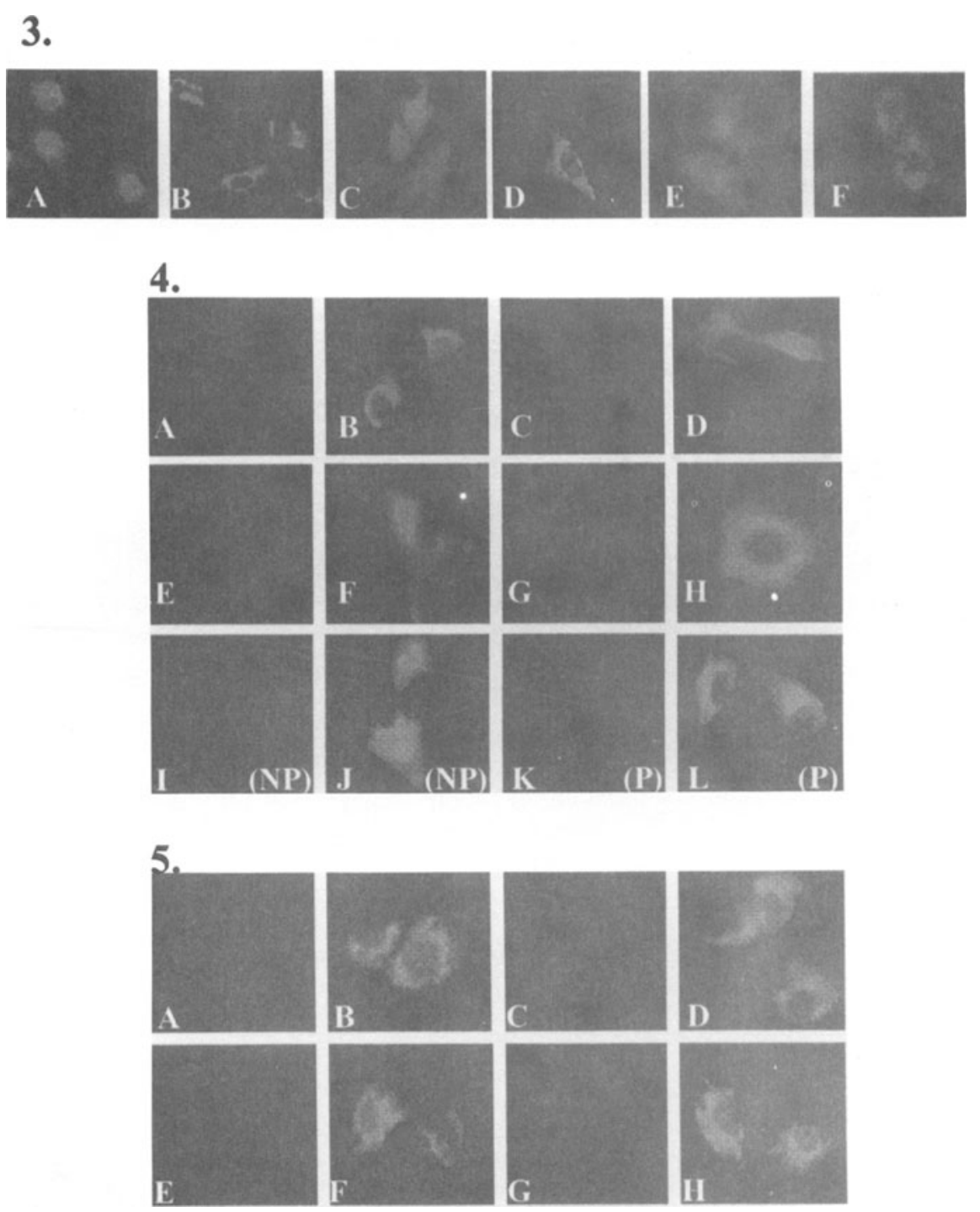

Figure 3. (A - F): Cos-7 cells overexpressing the GFP, 34-, 6-, 24-, 10- and 16-kDa proteins.

Figure 4. (A - L): Indirect immunofluorescence of Cos-7 cells overexpressing the 34-, 9-, 24-, 10- and 16-kDa proteins (NP: Non permeabilized; P: Permeabilized).

Figure 5. (A - H): Indirect immunofluorescence staining of Mock-infected (M) and IBV-infected (I) Vero cells with anti-6, anti-24, V47 and anti-16. 
Lim, K. P., Ng, L. F. P., and Liu, D. X., 2000, Identification of a novel cleavage activity of the first papain-like proteinase domain encoded by ORF la of the coronavirus avian infectious bronchitis virus and characterization of the cleavage products. J. Virol. 74: 1674-1685.

Liu, D. X., Brierley, I., Tibbles, K. W., and Brown, T. D. K., 1994, A 100kilodalton polypeptide encoded by open reading frame (ORF) $\mathrm{lb}$ of the coronavirus infectious bronchitis virus is processed by ORF la products. $J$. Virol. 68: 5772-5780.

Liu, D. X., Xu, H. Y., and Brown, T. D. K., 1997, Proteolytic processing of the coronavirus infectious bronchitis virus la polyprotein: identification of a 10kilodalton polypeptide and determination of its cleavage sites. J. Virol. 71: 1814-1820.

Liu, D. X., Shen, S., Xu, H. Y., and Wang, S. F., 1998, Proteolytic mapping of the coronavirus infectious bronchitis virus $1 \mathrm{~b}$ polyprotein: evidence for the presence of four cleavage sites of the $3 \mathrm{C}$-like proteinase and identification of two novel cleavage products. Virology 246: 288-297.

$\mathrm{Ng}$, L. F. P., and Liu, D. X., 1998, Identification of a $24-\mathrm{kDa}$ polypeptide processed from the coronavirus infectious bronchitis virus la polyprotein by the $3 \mathrm{C}$-like proteinase and determination of its cleavage sites. Virology 243: 388-395.

Ng, L. F. P., and Liu, D. X., 2000, Further characterization of the coronavirus infectious bronchitis virus $3 \mathrm{C}$-like proteinase and determination of a new cleavage site. Virology 272: (in press).

Ziebuhr, J., and Siddell, S. G., 1999, Processing of the human coronavirus 229E replicase polyproteins by the virus-encoded 3C-like proteinase: identification of proteolytic products and cleavage sites common to ppla and pplab. J. Virol. 73: $177-185$. 